\title{
Demographic Processes in the Kaliningrad Region in 2000-2014
}

\author{
Gennady M. Fedorov \\ Immanuel Kant Baltic Federal University, Russian Federation \\ Corresponding e-mail: GFedorov@kantiana.ru
}

\section{Doi:10.5901/mjss.2015.v6n6s7p84}

\begin{abstract}
The demographic processes in the Kaliningrad Region differ from other regions of the country significantly. The transmigrating nature of the population and the on-going migration growth are the conditioning factors for a more favourable demographic situation in the region. At the same time, contracted reproduction of population defines the reduction of the labour resources despite the significant influx of population from without. Development of economy should not be based on the growing number of the employed but on the increasing labour productivity and intersectoral redistribution of labour force. Additional supporting measures for families with children are necessary in order to lessen depopulation.
\end{abstract}

Keywords: Kaliningrad region, demographic processes, reproduction of population, forecast of labour resources

\section{Introduction}

The Kaliningrad Region is one of the few regions of the Russian Federation where population was formed as a result of an organized relocation which began in 1945. After August 1946, when a special programme was approved, the relocation assumed massive proportions. German population either left together with the retreating German troops or in 1948 was banished to Germany, mainly to Western Germany, in compliance with Potsdam Agreement. This process had almost finished by 1950. At present the population of the region is represented by migrants from various parts of the former Soviet Union (mainly Russia) and their descendants, while the number of the late German population or their descendants is insignificant. In 1959, the Germans amounted to $0.1 \%$ of the population of the region. By 2010 , this fraction has increased up to $1 \%$ due to the migrants from other regions of Russia and former USSR countries, mainly from Kazakhstan and Kyrgyzstan. In the first half of the 1990s, Kurt Widmaier and a number of German politicians raised a question concerning the relocation of the Germans from the post-Soviet territory to the Kaliningrad region, and turning the Region into an autonomous German republic. However, this initiative did not receive any support from either local or central administration in Russia; therefore, it has never been implemented (Fedorov \& Zverev, 1995).

The characteristic features of the demographic processes of the Kaliningrad Region are its migratory pattern and the exclave position of the region. These peculiarities are being studied in Immanuel Kant Baltic Federal University by the researchers in the fields of economic geography, politics, sociology and history (Fedorov, 2001, 2014; Kaliningrad socium..., 2002; Klemeshev, 2005; Klemeshev \& Fedorov, 2004; Kuznetsova \& Fedorov, 2011).

This article takes into consideration the results of the conducted researches and analyses the statistical data, which characterizes the demographic situation in the Kaliningrad Region in 2000 - 2014.

\section{Demographic Processes in 1945-1999}

In the early 1950s, the role of the migrants' inflow in the population growth in the region had already diminished, and natural population upsurge remained the main population growth factor up until the late 1980s. In the 1990s, the population growth due to the influx of migrants regained its significance. After the dissolution of the Warsaw Treaty Organization, the Baltic republics' proclamation of independence and the following break-up of the USSR, the Kaliningrad Region faced the arrival of the Soviet troops from Czechoslovakia and the Baltic states. Afterwards, there was a considerable inflow of Russian population from the Baltic, Transcaucasia states, Kazakhstan, and Central Asia.

In the 2000s, the population dynamics in the region was determined by both the natural population growth and the significant migration inflow. Due to the proportions of that inflow around early 1990s, the share of region natives had decreased to $40 \%$, while in late 1980 s we estimated it to reach up to $44 \%$ of the population. It hinders the formation of a stable regional society with established structure and sustainable social ties. 
We can mark out five stages of formation of the present-day population of the region, which are characterized by the population dynamics and the role of external migrations:

- 1945 - 1948: mass settlement; population formed due to the migrants' inflow mainly from the European part of Russia;

- 1949 - 1991: the role of migration growth diminished, and the natural population growth prevailed; up to the mid-1960s the natural population growth remained high but showed a falling tendency later;

- 1992 - 1998: reinstating of migration growth, which caused the general increase of population in the region despite the natural decline in population due to excess of mortality over birth-rate;

- 1999 - 2007: decline in migration growth, which, when combined with the progressing natural decline in population, became the determine factor in the general population decline in the region.

- 2008 - present time (the middle of 2015): natural increase in population due to surplus of birth over death and migration growth which lead to general population growth in the region.

Table 1 demonstrates the role of natural and migration fluctuations in the dynamics of the population size of the region.

Table 1. Annual average rates of increase (reduction) of the size of population in the Kaliningrad Region, $\%$

\begin{tabular}{lccccccccccccccc}
\hline \multirow{2}{*}{ Growth } & $1948-1950-1955-1960-1965-$ & $1970-$ & $1975-1980$ & $1985-$ & 1990 & $-1995-2000-$ & $2005-2010-$ \\
& 1949 & 1954 & 1959 & 1964 & 1969 & 1974 & 1979 & 1984 & 1989 & 1994 & 1999 & 2004 & 2009 & 2014 \\
\hline Natural & 3.5 & 3.2 & 2.2 & 1.6 & 1.0 & 1.0 & 0.8 & 0.7 & 0.6 & 0.1 & -0.6 & -0.8 & -0.6 & -0.2 \\
Migration & 0.0 & 4.0 & 0.7 & 0.5 & 0.1 & -0.3 & 0.0 & 0.0 & 0.2 & 1.1 & 0.9 & 0.4 & 0.5 & 0.8 \\
Total & 3.5 & 7.5 & 2.9 & 2.1 & 1.1 & 0.7 & 0.8 & 0.7 & 0.8 & 1.0 & 0.3 & 0.4 & 0.1 & 0.6 \\
\hline
\end{tabular}

Source: Compiled by the author on basis of the following data: Rosstat, 2011; Regions of Russia, 2002; 2014.

In comparison to the Russia's average, the population dynamics in the Kaliningrad Region always differed significantly (see Table 2).

Table 2. Population growth (decline) comparison between the Kaliningrad Region and the Russian Federation

\begin{tabular}{lcccccc}
\hline & \multicolumn{7}{c}{ Population growth (decline) in the period, \% } \\
\cline { 2 - 7 } & $1959-1970$ & $1970-1979$ & $1979-1989$ & $1989-2002$ & $2002-2007$ & $2008-2013$ \\
\cline { 2 - 7 } Kaliningrad Region & 19.8 & 10.2 & 7.9 & 9.6 & -0.6 & 2.8 \\
Russian Federation & 10.7 & 5.7 & 7.1 & -1.3 & -1.4 & 1.2 \\
\hline
\end{tabular}

Source: Compiled by the author on basis of the following data: (Rosstat, 2011; Regions of Russia, 2002; 2014.

Until the 1980s there was a much faster population growth in the Kaliningrad Region, which gradually slowed down to match the averages in the Russian Federation. In the 1980s, the demographic situation in the region levelled with that in the 'average', well-developed regions of Russia. The differences in the population dynamics from the averages in Russia became insignificant. However, the 1990s brought some changes to the situation. While the natural fluctuations of the population were close to the Russia's averages, the dynamics of the population in the region turned out to be more favourable due to higher migration inflow. It was in 1992 that Russia first experienced the decline in population, but in the Kaliningrad Region this process did not start before 1999. In the period between the population censuses in 1989 and 2002 the Russian Federation saw the decline in population, while the Kaliningrad Region boasted a significant increase. After 2002, the population dynamics in the region bore more resemblance to the average in the country. Still, the period of 2002 - 2007 showed a slower decline in population in comparison to the averages in the Russian Federation, and in the subsequent period there was a population growth due to the indications of natural and, more importantly, migration growth.

\section{Population Dynamics in the Kaliningrad Region in 2000 - 2014}

The population size in the Kaliningrad Region on January 1, 2015 amounted to 968,300 people, having increased in comparison to 2000 by 9,500 people. The region is firmly settled and highly urbanized. Population density is 64.1 people 
per sq. kilometres versus 8.7 people per sq. kilometres in an average in the Russian Federation. Urban population reaches $77.6 \%$ (the Russian Federation average $-74.2 \%$ ).

In 2000 - 2007 the population of the region shrank, the process started in 1999, when the population size dropped to 961,300 people. In 2007 the population size plummeted down to 934,300 people; starting from 2008 it had been rebuilding and in 2014 it exceeded the previous maximum of 1999 (see Figure 1).

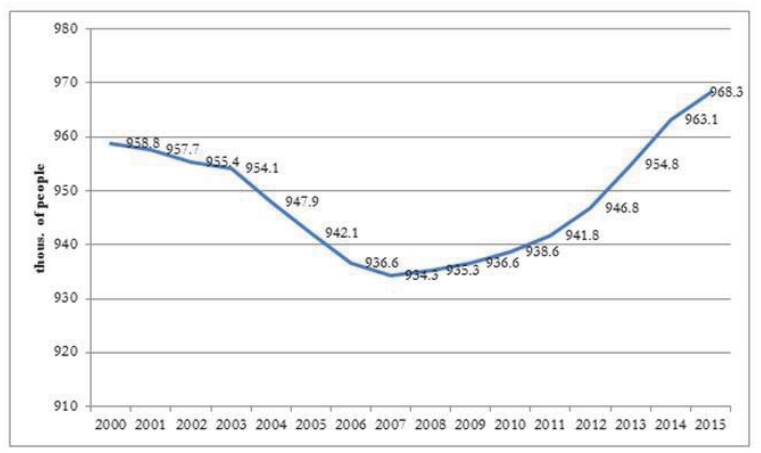

Figure 1. Population size dynamics in the Kaliningrad Region, 2000 - beginning of 2015.

Source: (Kaliningradstat, 2014; Russia: Best Places for Living, 2015).

The population size reduction can be explained by the increase of natural decline in population and the decrease of migration growth in 2000 - 2005 (see figure 2). The subsequent increase of birth-rate and migration growth led to the fact that in 2007 migration growth exceeded natural decline in population. Migration growth and general increase in population peaked in $2012-2013$, having somewhat decreased in 2014. However, the natural decline in population, which dropped to 0.6 units per 1000 inhabitants in 2014, still did not turn into natural population growth.

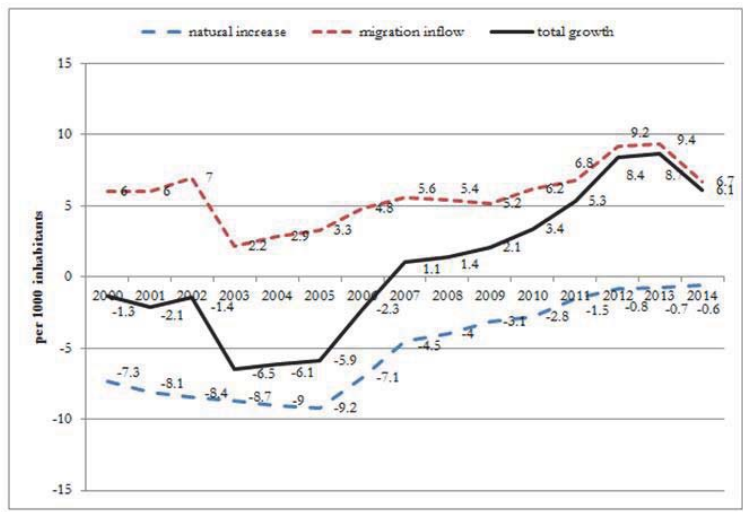

Figure 2. Components of the population size dynamics in the Kaliningrad Region, 2000 - 2014.

Source: Compiled by the author on basis of: Kaliningradstat (2014); Russia: Best Places for Living (2015).

The characteristic features of natural population fluctuations in 2000 - 2015 are typical for the overwhelming majority of the subjects of the Russian Federation (with an exception of several republics and autonomous districts with a high birth rate) and can be mostly explained by a slow increase of birth rate during this period. Another reason is the increasing death rate up to 2004, and its gradual decrease, which started in 2006 (see Figure 3). 


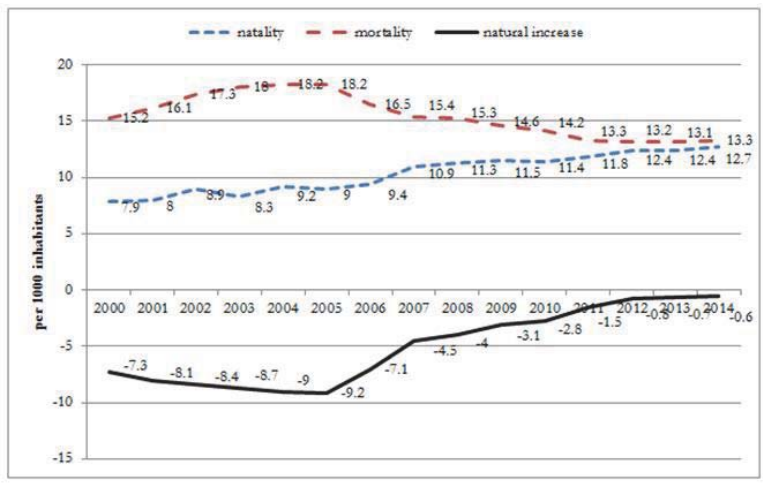

Figure 3. Dynamics of natural fluctuation of population in the Kaliningrad Region, 2000 - 2014.

Source: Compiled by the author on basis of: Kaliningradstat (2014); Russia: Best Places for Living (2015).

The increase of birth rate is partially due to the improving standards of living but introduction of the maternity capital measure on January 1, 2015 proved to be the most effective in this respect. ${ }^{1}$ Women in the age group of $25-44$ were keener on giving birth to the second child, which boosted the birth rate.

The reduction of mortality rate was caused by the grown life interval, which in its turn was caused by the significantly improved standard of living in the 2000s. In 2000, the average life interval in the Kaliningrad Region was lower than in the Russian Federation: $\mathbf{5 7 . 6}$ years for males (which is 2.4 years less than the retirement age) and 70.7 years for females. In the 2000s, the life interval in the region had been growing faster than the average in the Russian Federation, which brought the region from the 66th to the 29th position among the subjects of the Russian Federation. The average life interval caught up with the average of 65.1 years for men and 75.7 for women (which is 0.6 year less than in the Russian Federation).

The age and gender diversity of the Kaliningrad Region differs from the average in the Russian Federation in regard to the transmigratory nature of its population and the ongoing migration growth. The region boasts a bigger share of employable population, while following its general dynamics in the Russian Federation (growth in $2000-2005$ and the subsequent decrease).

There are fewer children in the region compared to the Russian Federation, but more than in the North-western Federal District, which also matches the pattern of 2000 - 2015: initial decline with subsequent growth accompanied by increasing birth rate.

In 2000, the share of retired people in the Kaliningrad Region was below the average in the Russian Federation in general and in the Northwestern Federal District in particular, and it grew quite rapidly due to a longer life interval. By 2013 it has become equivalent to an average in the Russian Federation.

The peculiarities of the age structure of the population are the determinative factor of employable/unemployable demographic ratio in the region in comparison to the Russian Federation.

The ratio of people under employable age is lower than in the Russian Federation (273 to 1000 able-bodies citizens vs. 290 to 1000 able-bodies citizens). The ratio of people over employable age is lower than in the Russian Federation (391 to 1000 able-bodies citizens vs. 397 to 1000 able-bodies citizens). It is conditioned by the increased share of people of employable age in the region. Therefore, the cumulative ratio of employable/unemployable people in the region is lower in comparison to the Russian Federation: 664 to 1000 able-bodies citizens vs. 687 to 1000 ablebodies citizens in the Russian Federation.

Not only gender ratio in the Kaliningrad Region differs from the average in the Russian Federation, but also the trends of the dynamics of such a ratio are very different. In 2000 - 2014 women prevailed in number both in the Russian Federation and in the Kaliningrad Region. In the beginning of the year the proportion of women to men dwindled from 1133 females per 1000 males to 1073 females per 1000 males in the Russian Federation, and from 1159 females per

\footnotetext{
${ }^{1}$ Maternity capital is the measure of state support of the families, in which a second, third, etc. child is born or adopted in 2007 - 2016, if maternity capital had not been obtained previously. Initially the maternity capital was set at 250,000 rubles but the sum is adjusted annually. In 2015 the maternity capital is 453,026 rubles. Mothers are only allowed to use the money for three purposes: to buy housing or make mortgage payments, to sponsor the child's education, or to augment their accumulated pension (FL, 2006).
} 
1000 males to 1129 females per 1000 males. This is due to the fact that in the period of 2000 - 2013 the gap in the life expectancy went down from 13.2 years in 2000 (59.0 years for males, 72.2 years for females) to 11.2 years in 2013 (65.1 years for males, 76.3 years for females).

Just like in the majority of countries, the overall "female numerical superiority" in Russia is explained by a longer life interval for women. A smaller male/female ratio in the Kaliningrad Region is explained by the characteristics of the economy of the region. A big number of young men come to the region looking for a job with the fishing or mercantile fleet, international transportation, border trade; there are also departmental colleges that mostly teach male students. Men outnumber women in the age group up to 33 years old, but this disproportion is particularly significant in $15-25$ year old age groups. From the age of 34 the numerical superiority of female population grows increasingly only to surge up after the age of 50 .

The peculiarities of age and gender structure of the population of the region for the next 15 years define the perspectives of the labour resources dynamics (those that can be adjusted with consideration for migration dynamics).

Using the data on age and gender structure of the population in 2014 and the information of the present-day age mortality, we were able to make a forecast of the size of employable population for the period of up to 2030, provided that the annual migration balance will remain at 9,000 people per year, as in 2013 (see Figure 4).

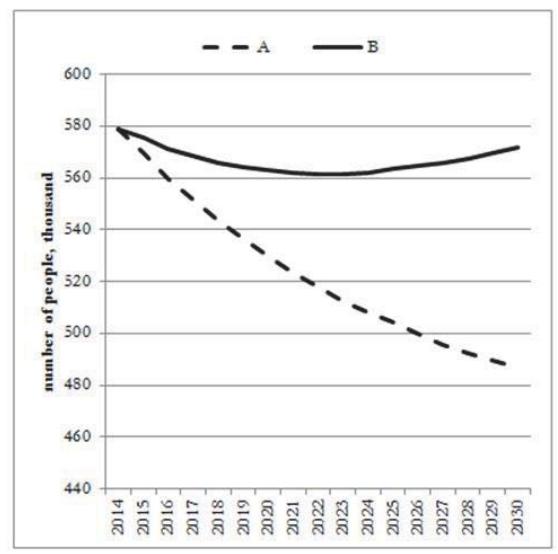

Figure 4. Forecast of the size of employable population in the Kaliningrad Region, 2014 - 2030, thousands of people

A - includes age mortality, ignores migration;

B - includes age mortality and annual migration balance of 9,000 people per year.

The curves in Picture 4 show the dynamics of the population size, where the annual inflow of 9,000 migrants a year is not enough to make up the deficiency of employable population, and lack of migration leads to its drastic reduction.

\section{Conclusion}

Contracted reproduction of population combined with reduction of the labour resources, which is typical for the Kaliningrad Region and the overwhelming majority of Federation subjects (with an exception of some republics), cause depopulation. The situation is alleviated by the influx of population from other regions of Russia and its bordering countries, Kazakhstan, Kyrgyzstan, and Uzbekistan in particular. Until recently, this influx served as a guarantee against population decrease and provided a stable number of labour resources. However, even the influx of 9,000 migrants a year will be insufficient for maintaining a current number of labour resources.

In order to increase the number of employed people (provided there would be new jobs created), the industry will have to engage the currently unemployed people as well as senior citizens. Should a much discussed initiative of possible raise of retirement age be implemented, it will, to a certain extent, cause the increase of labour resources, as a significant number of pensioners is still employed, especially those who are in their first five-year period of retirement. It appears a good policy to switch from the extensional industrial growth through job creation to growth through labour productivity and inter-branch redistribution of the employed. 
The maternity capital programme will remain effective up till the end of 2016 , and to a certain extent will positively affect the increase of birth rate Similar to the majority of the European countries, depopulation is a common process in the Russian Federation at large and in the Kaliningrad Region in particular. In order to manage the present day situation, it is necessary to not only extend the maternity capital programme, but also to look for additional measures from which families with children will benefit.

\section{References}

Fedorov, G.M. (2001). Population of the Kaliningrad Region. Kaliningrad: KSU Press.

Fedorov, G.M. (2014). Current Trends in Demographic Research in Russia. Baltic region, 2(20), 7-28.

Fedorov, G.M. (2014). The concept of geo-demographic situation and geo-demographic typology of the subjects of the Russian Federation. Bulletin of Geography, 25, 101-114.

Fedorov, G.M., \& Zverev, Yu.M. (1995). Kaliningrad Alternatives. Kaliningrad: KSU Press.

FL (2006). On additional measures of support of families with children. Federal Law of December 29, 2006, no. 256-FZ. Available at: http://base.garant.ru/12151286/ [in Russian]

Kaliningrad socium in European Context (2002). Kaliningrad: KSU Press.

Kaliningradstat (2015). The demographic Yearbook of Kaliningrad oblast. 2014. Kaliningrad: Publ. Kaliningradstat.

Klemeshev, A.P. (2005). Russian Exclave: Overcoming the Conflictogenity. SPbGU Press. [in Russian]

Klemeshev, A.P., \& Fedorov, G.M. (2004). Kaliningrad Socium: Based on the Results of Sociological Surveys of 2001-2004. Region sotrudnichestva, 6 (31), 1-50. [in Russian]

Regions of Russia (2002). Socio-Economic Indicators. Moscow: Goscomstat of Russia.

Regions of Russia (2014). Socio-Economic Indicators. Moscow: Rosstat.

Rosstat (2011). The demographic Yearbook of Russia. 2010. Statistical Handbook. Moscow: Rosstat.

Russia: Best Places for Living (2015). The key indicators of a socio-economic situation of subjects of the Russian Federation in 2014. Rossyskaya gazeta, March.

Kuznetsova, T.Yu, \& Fedorov, G.M. (2011). Territorial Differentiation of Demographic Development of the Countries of the Baltic Macroregion. Vestnik RGU im. I.Kanta, Estestvennye nauki, 1, 131-137. [in Russian] 